\title{
Diyabetlilerde tatlandırıcı ve diyet/diyabetik ürün kullanım durumu
}

Bedriye URAL ${ }^{\mathrm{a}}$, Müveddet Emel ALPHAN

\section{ÖZET}

Amaç: Diyabetliler tıbbi beslenme tedavilerinin içerisinde çeşitlilik yaratmak adına tatlandırıcı ve diyet/diyabetik ürünler kullanabilirler. Bu çalışmanın amacı diyabetlilerin tatlandırıcı ve diyet/diyabetik ürün kullanım durumlarını, kullanma ve kullanmama nedenlerini saptamaktır. Yöntem: Bu araştırma Ekim-Aralık 2017 tarihleri arasında özel bir hastaneye başvuran 85’i (\%63.4) kadın, 49’u (\%36.6) erkek olmak üzere toplam 134 yetişkin diyabetli ile yapılmıştır. Yüz yüze görüşme yöntemi ile hastaların demografik verileri (yaş, cinsiyet, diyabet tipi, eğitim seviyesi vb.) ile tatlandırıcı ve diyet/diyabetik ürün kullanımına dair bilgiler alınıp kaydedilmiştir. Bulgular: Çalışmaya katılanların \%79.1'inin herhangi bir tatlandırıcı kullanmadıkları belirlenmiştir. Tatlandırıcı veya tatlandırıcılı ürün tüketmeme sebeplerinin "sağlığa zararlı olduğu" (\%41.5), "tadını beğenmediği" (\%27.7), "fiyatını pahalı bulduğu" (\%7.4) şeklinde olduğu belirlenmiştir. Tatlandırıcı ve tatlandırıcılı ürün tüketenlerin ise \%40'ının şeker içermemesi ve \%27.5'inin ise enerji içermemesi nedeniyle tercih ettikleri saptanmıştır. Diyabetlilerin diyet/diyabetik ürünleri tercih durumlarına bakıldığında; diyet ürünler içerisinde en çok diyet bisküvi/krakerler (\%17.2), daha sonra diyet içecekler (\%13.4) ve sırasıyla light meyveli yoğurt (\%11.9), diyet sütlü tatlılar (\%9), diyet dondurma (\%8.2), diyabetik reçel/marmelat (\%6), diyabetik çikolata (\%5.2) ve diyet hamurlu tatlı (\%3) tüketilmektedir. Sonuçlar: Bu çalışmanın sonucunda diyabetlilerin tatlandırıcılar konusunda yeterli ve doğru bilgiye sahip olmadıkları ve tatlandırıcı ile diyabetik ürün kullanımları düşük bulunmuştur. Diyabetlilerin sağlıklı beslenme uygulamaları çerçevesinde şeker yerine tatlandırıcılar ve diyet/diyabetik ürünleri kullanabilecekleri konusunda bilinçlendirilmeleri gerekir.

Anahtar kelimeler: Diyabetes Mellitus, diyet/diyabetik ürünler, tatlandırıcılar

\section{Sweetener and diet/diabetic product use in diabetics}

\begin{abstract}
Objective: Diabetics can use sweeteners and diet/diabetic products to create diversity within their medical nutritional therapies. The purpose of this study is to determine the consumption of sweeteners and diet/diabetic products, reasons for using/not using them. Methods: The study was conducted between October and December 2017 with a total of 134 adult participants, 85 $(63.4 \%)$ female and $49(36.6 \%)$ male who referred to a private hospital with a diagnosis of diabetes. Demographic variables (age, sex, diabetes type, education level, etc.) and consumption of sweeteners and diet/diabetic products were recorded in the questionnaire form by face to face interview method. Results: It was determined that $79.1 \%$ of the participants did not use any sweeteners. The most common reasons for not using were "harmful to health" (41.5\%), "dislike taste" (27.7\%) and "expensive price" (7.4\%). $40 \%$ of the diabetics prefer sweeteners and diet/diabetic products because they do not contain sugar and $27.5 \%$ of them prefer sweeteners and diet/diabetic products because they do not contain calories Diabetics mostly prefer diet biscuits/crackers (17.2\%), diet drinks (13.4\%), light fruity yogurt (11.9\%), diet puddings (9\%), diet ice cream $(8.2 \%)$, diabetic jam (6\%), diabetic chocolate (5.2\%) and diet dessert (3\%). Also, it was found that females cook much more homemade desserts with sweeteners than males do. Conclusions: It has been found that diabetics do not have enough knowledge about sweeteners and their consumption of sweeteners or diabetic products is low. Diabetics need to be aware that they can use sweeteners and diet/diabetic products instead of sugar in the context of healthy nutritional practices.
\end{abstract}

Key words: Diabetes Mellitus, diet/diabetic products, sweeteners

\footnotetext{
Geliș Tarihi: 20.09.2019 Kabul Tarihi:03.11.2019

a'stanbul Okan Üniversitesi, Sağlı Bilimleri Fakültesi, Beslenme ve Diyetetik Bölümü, İstanbul, Türkiye, e-posta: bedriye.ural@okan.edu.tr, https://orcid.org/0000-0001-8569-8943

bístanbul Okan Üniversitesi, Sağlık Bilimleri Fakültesi, Beslenme ve Diyetetik Bölümü, İstanbul, Türkiye, e-posta: emel.alphan@okan.edu.tr, https://orcid.org/0000-0002-9702-1881

Sorumlu Yazar/Correspondence: Bedriye Ural e-mail: bedriye.ural@okan.edu.tr
}

Çalışma yüksek lisans tezinden türetilmiştir, 1. Uluslararası Sağlık Bilimleri ve Yaşam Kongresi'nde Sözel Bildiri olarak sunulmuştur.

Atıf: Ural B, Alphan ME. Diyabetlilerde tatlandırıcı ve diyet/diyabetik ürün kullanım durumu. Săgllk ve Yaşam Bilimleri Dergisi 2019;1(2):19-23.

Citation: Ural B, Alphan ME. Sweetener and diet/diabetic product use in diabetics. Journal of Health and Life Science 2019;1(2):19-23. 


\section{GíRiş}

Beslenme, yaşamın devam ettirilmesi, büyüme ve gelişmenin sağlanması, hastalıklardan korunmak ve sağlığın korunması için besin ögelerinin vücuda yeterli ve dengeli miktarlarda alınmasıdır. Besin tercihleri, besinlerin tadına, kokusuna ve dokusuna verilen duyusal tepkiler ile belirlenir. Tat tercihlerini belirleyen etmenler arasında biyolojik, kültürel, çevresel, sosyoekonomik, psikolojik vb. pek çok faktör sayılabilir. ${ }^{1}$

Insanlar, tatlı tadı her zaman sevmiş ve yiyeceklerine eklemişlerdir. Bilinen ilk tatlandırıcı besin baldır. Balın yerini daha sonraları üretim kolaylığı ve düşük maliyeti ile şeker almıştır. ${ }^{2}$

Şeker içeren ürünlerin tüketiminin artması, fiziksel aktivitenin azlığı ve düzensiz beslenme obezite, diyabet, kalp damar hastalıkları, hipertansiyon gibi hastalıkların risk faktörleri olarak gösterilmektedir. Yüksek miktarlarda tüketilen basit karbonhidratlar, kan şekerini yükseltip hiperinsülinemiye neden olabilir. Glikoz metabolizmasının bozulması sonucu insülin direnci ve daha ileri dönemlerde tip 2 diyabet görülebilmektedir. ${ }^{3,4}$ Diyabetin tedavisinde ise tıbbi beslenme tedavisinin önemi çok büyüktür. ${ }^{5}$

Tatlandırıcılar şeker yerine kullanılabilen ve şekere kıyasla oldukça yüksek tatlılığa sahip bileşiklerdir. Yiyecek veya içeceklerde çok küçük miktarlarda kullanılarak istenilen tatlı tadını verirken, oldukça az veya hiç enerji sağlamaması, kan şekerini yükseltmemesi gibi nedenlerle tercih edilmektedir. ${ }^{6-9}$ Tatlandırıcılar; şeker tadı verebilen, çözelti halindeyken renksiz, kokusuz, suda çabuk eriyebilen, ekonomik, fonksiyonel, ısıya dayanıklı ve düşük kalorili olmalı, ağızda acı ve metalik tat bırakmamalı, ayrıca toksik ve kanserojen özellik göstermemelidir. ${ }^{10}$

Tatlandırıcılar, düşük enerji içeren şeker alkolleri (polioller) ile enerji içermeyen tatlandırıcılar olarak sınıflandırılabilir. Şeker alkollerine örnek olarak sorbitol, mannitol, ksilitol, eritritol, isomalt, laktilol verilebilir. Enerji içermeyen yapay tatlandırıcılardan sakarin, sükraloz, aspartam, asesülfam potasyum, neotam ve advantame, Amerikan Besin ve İlaç İdaresi (U.S. Food and Drug Administration - FDA) tarafindan besinlerde tatlandırıcı olarak kullanılma onayı almış ve GRAS madde (genel olarak güvenli) olarak tanımlanmıştır. ${ }^{11}$

Günümüz besin endüstrisinde yapay tatlandırıcılar "şekersiz" veya "diyet" adı altında pek çok içecekte, yoğurt, tatlı, sakı, puding, konserve ürünler, jeller, şekerler, süt ürünleri, çikolata, gibi besinlerde oldukça yaygın kullanılırlar.9, 12 Ürünlerde istenilen tatlı tada ulaşmak için tatlandırıcılar genellikle karışım halinde kullanılır. ${ }^{13}$ Sorbitol, mannitol ve ksilitol gibi enerjisi düşük olan şeker alkolleri (polioller) sofra şekeri olan sukroza göre daha düşük glisemik yanıt oluşturan tatlandırıcılardır. ${ }^{14-16}$ Şeker alkollerinin aşırı miktarda tüketilmeleri, laksatif etkiye yol açtığ gibi, örneğin, aşırı sorbitol alınması da nöropati riskini artırabilir. Enerji içeren tatlandırıcılardan fruktozun da aşırı miktarlarda alınması da laksatif etki ve dislipidemi riskinin artmasına yol açar. ${ }^{17}$

Şeker yerine geçen maddeler veya yapay tatlandırıcılar düşük enerji içerikleri ve kan şekerini yükseltmemesi ile popülerlik kazanmıştır. Diyabetliler, yapay tatlandırıcıları tatlı ihtiyaçlarını karşılamak için yiyecek ve içeceklerinde kullanırlar. Son on yılda, özellikle çocuklarda tatlandırıcı içeren yiyecek ve içeceklerin tüketimi oldukça artmıştır. ${ }^{18}$ Ancak tatlandırıcılar ile ilgili yazılı ve görsel medyada çıkan haberler, bireylerde kafa karışıklığına sebep olmuştur. $\mathrm{Bu}$ nedenle daha fazla araştırmanın yapılması sağlık çalışanlarının, bireylerin ve özellikle diyabetlilerin bu konuda eğitilmesi gerekliliği ortaya çıkmıştır.

Bu çalışma diyabetlilerin tatlandırıcı ve diyet/diyabetik ürün kullanım durumlarını, kullanma ve kullanmama nedenlerini saptamak amacı ile yapılmıştır.

\section{YÖNTEM}

Araştırma Ekim-Aralık 2017 tarihleri arasında özel bir üniversite hastanesinde kesitsel bir çalışma olarak yapılmıştır. Araştırmanın örneklemini, çalışmaya katılmayı kabul eden 85'i (\%63.4) kadın, 49’u (\%36.6) erkek olmak üzere diyabet tanısı almış toplam 134 yetişkin katılımcı oluşturmaktadır.

Anket çalışması için İstanbul'da bulunan bir vakıf üniversitesinin etik kurulundan (87 sayılı 08.09.2017 tarihli) "Etik Kurul Onayı" alınmıştır. Araştırmada gönüllülük esas alınmış ve katılımcılara “ Gönüllü Katılım Formu" imzalattırılmıştır.

Anket formu araştırmacı tarafindan oluşturulan yedi demografik soru (yaş, cinsiyet, eğitim durumu, diyabet tipi, diyabet yaşı vb.) ve tatlandırıcı ile diyet/diyabetik ürün kullanım durumunu belirlemeye yönelik sorulardan oluşmaktadır. Araştırmaya alınan bireylerin genel bilgilerinin yanı sira, tatlandirıc1 ve diyet/diyabetik ürünlerini kullanım durumu, bu ürünleri kullanma ve kullanmama nedenleri saptanmıştır. Anket formu araştırmacı tarafindan çalışmaya katılmayı kabul eden diyabetlilere yüz yüze görüşme yöntemi ile uygulanmıştır.

Verilerin analizinde SPSS 21.0 istatistik programı kullanılmıştır. Tanımlayıcı istatistik bağlamında katılımcıların demografik verilerine (cinsiyet, öğrenim durumu, diyabet tipi) ve araştırma sorularına verdikleri yanıtlara yönelik frekans (s), yüzde (\%) değerlerine bakılmıştır. Bireylerin yaş, boy, ağırlık, diyabet yaşı, 
Beden Kütle İndeksi (BKİ) verilerinin, ortalama değer ve standart sapmaları belirlenmiştir. Katılımcılar diyet içecek, diyet/diyabetik ürün ve yapay tatlandırıcı kullanım durumları, tatlandırıcı veya tatlandırıcılı ürün kullanım nedenleri ve kullanmama nedenleri açısından değerlendirilip frekansları bulunmuştur. Katılımcıların tükettikleri diyet/diyabetik ürünler cinsiyete göre ve diyabet tipine göre karşılaştırılmıştır. Elde edilen bulgular $\% 95$ güven aralığında, $\% 5$ anlamlılık düzeyinde değerlendirilmiştir (Anlamlılık düzeyi: $\mathrm{p}<0.05$ ). İki değişkenin analizinde sistemli bir ilişkinin olup olmadığını belirlemek için frekans dağılımına dayanan Ki kare testi (Chi-square) kullanılmıştır.

\section{BULGULAR}

Çalışmaya 18 ile 65 yaş aralığında yetişkin 85'i (\%63.4) kadın, 49’u (\%36.6) erkek olmak üzere toplam 134 diyabetli birey katılmıştır. Katılımcıların BKI'leri \%43.3'ünün 25.1-30 arasında, normal BKİ aralığında olan bireylerin oranının ise \%13.4 olduğu belirlenmiştir. Çalışmaya katılan bireylerin diyabet tipi dağılımına bakıldığında ise \%11.9'u tip 1 diyabetli iken \%88.1'i ise tip 2 diyabetlidir (Tablo 1).

Tablo 1. Katılımcıların demografik bilgileri

\begin{tabular}{llll}
\hline & & s & $\%$ \\
\hline \multirow{2}{*}{ Cinsiyet } & Kadın & 85 & 63.4 \\
& Erkek & 49 & 36.6 \\
\hline \multirow{3}{*}{ BKİ $\left(\mathbf{k g} / \mathbf{m}^{\mathbf{2}}\right)$} & $18.5-25.0$ & 18 & 13.4 \\
& $25.1-30.0$ & 58 & 43.3 \\
& $30.1-35.0$ & 39 & 29.1 \\
& +35.1 & 19 & 14.2 \\
\hline \multirow{2}{*}{ Öğrenim Durumu } & İlköğretim & 62 & 46.3 \\
& Lise & 30 & 22.4 \\
\multirow{2}{*}{ Diyabet Tipi } & Üniversite & 42 & 31.3 \\
\hline
\end{tabular}

Katılımcıların \%79.1'inin $\quad(\mathrm{s}=94) \quad$ tatlandırıcı kullanmadıkları belirlenmiştir. Çalışmaya katılan diyabetlilerin tatlandırıcı veya tatlandırıcılı ürün kullanma ve kullanmama nedenlerine göre dağılımları Tablo 2'de gösterilmiştir.

Tablo 2. Katılımcıların tatlandırıcı veya tatlandırıcılı ürün kullanma ve kullanmama nedenlerine göre dağılımları

\begin{tabular}{|c|c|c|c|}
\hline & & $\mathbf{S}$ & $\%$ \\
\hline \multirow{5}{*}{$\begin{array}{l}\text { Tatlandırıcı veya } \\
\text { tatlandırıcılı } \\
\text { ürünleri kullanım } \\
\text { nedenleri }(s=40)\end{array}$} & Şeker içermemesi & 16 & 40.0 \\
\hline & Kalori içermemesi & 11 & 27.5 \\
\hline & $\begin{array}{l}\text { Diyetisyen/doktor } \\
\text { önerisi }\end{array}$ & 9 & 22.5 \\
\hline & Arkadaş/akraba önerisi & 3 & 7.5 \\
\hline & Diğger & 1 & 2.5 \\
\hline \multirow{4}{*}{$\begin{array}{l}\text { Tatlandırıcı veya } \\
\text { tatlandırıcılı } \\
\text { ürünleri } \\
\text { kullanmama } \\
\text { nedenleri }(s=94)\end{array}$} & $\begin{array}{l}\text { Sağlığa zararlı olduğunu } \\
\text { düşünen }\end{array}$ & 39 & 41.5 \\
\hline & Tadını beğenmeyen & 26 & 27.7 \\
\hline & Fiyatını pahalı bulan & 7 & 7.4 \\
\hline & Diğer & 22 & 23.4 \\
\hline
\end{tabular}

Çalışmaya katılan diyabetlilerin en fazla diyet bisküvi/kraker (\%17.2) tükettiği, daha sonra ise sırasıyla diyet içecek $(\% 13.4)$, light meyveli yoğurt (\%11.9), diyet dondurma (\%8.2), diyabetik reçel/marmelat (\%6), diyet çikolata $(\% 5.2)$, diyet sütlü tatlı (\%9.0) ve diyet hamurlu tatlı (\%3) tükettiği görülmüştür (Tablo 3 ).

Tablo 3. Diyet/diyabetik ürün tüketim dağılımları

\begin{tabular}{|c|c|c|c|}
\hline & & $\mathbf{s}$ & $\%$ \\
\hline \multirow{2}{*}{$\begin{array}{l}\text { Diyet içecekler (kola, } \\
\text { soda, soğuk çay, meyve } \\
\text { suyu vb.) }\end{array}$} & Tüketen & 18 & 13.4 \\
\hline & Tüketmeyen & 116 & 86.6 \\
\hline \multirow{2}{*}{$\begin{array}{l}\text { Diyet bisküviler, } \\
\text { krakerler }\end{array}$} & Tüketen & 23 & 17.2 \\
\hline & Tüketmeyen & 111 & 82.8 \\
\hline \multirow{2}{*}{ Diyet dondurma } & Tüketen & 11 & 8.2 \\
\hline & Tüketmeyen & 123 & 91.8 \\
\hline \multirow{2}{*}{ Diyet çikolata } & Tüketen & 7 & 5.2 \\
\hline & Tüketmeyen & 127 & 94.8 \\
\hline \multirow{2}{*}{ Diyet sütlü tatlı } & Tüketen & 12 & 9.0 \\
\hline & Tüketmeyen & 122 & 91.0 \\
\hline \multirow{2}{*}{$\begin{array}{l}\text { Diyet hamurlu tatlı (diyet } \\
\text { baklava, diyet şekerpare } \\
\text { vb.) }\end{array}$} & Tüketen & 4 & 3.0 \\
\hline & Tüketmeyen & 130 & 97.0 \\
\hline \multirow{2}{*}{ Light meyveli yoğurt } & Tüketen & 16 & 11.9 \\
\hline & Tüketmeyen & 118 & 88.1 \\
\hline \multirow{2}{*}{ Diyabetik reçel, marmelat } & Tüketen & 8 & 6.0 \\
\hline & Tüketmeyen & 126 & 94.0 \\
\hline
\end{tabular}

\section{TARTIŞMA}

Tip 2 diyabet (Tip 2 DM) prevalansı ülkemizde ve tüm dünyada artmaktadır. İki bin on yılında yayınlanan Türkiye Diyabet ve Epidemiyolojisi Prevalans Çalışması II (TURDEP II) verilerine göre diyabet kadınlarda \%14.6, erkeklerde \%12.4 ve genelde \%13.7 oranında görülmektedir. ${ }^{3}$ Dünya Sağlık Örgütü'nün (DSÖ) 2014 verilerine göre dünya genelinde obezite 1980 yılına göre ikiye katlanmış, 18 yaş ve üzeri bireylerde \%39 fazla kilolu, \%13 oranında obezite olduğu belirlenmiştir. ${ }^{19}$ Amerikan Diyabet Birliğinin (ADA) raporuna göre; Amerika Birleşik Devletleri'nde (ABD) diyabetin ölüme yol açan hastalıkların yedinci sırasında olduğu ve 30.3 milyon kişinin diyabetli olduğu ve bu diyabetlilerin 7.2 milyonuna tanı konulmadığ 1 bildirilmiştir. ${ }^{20}$

Tip 2 DM gelişimini etkileyen risk faktörlerinin başında kentleşmeyle bağlı sedanter yaşam tarzı, yağ içeriği yüksek besinler, şekerli içecekler ve rafine edilmiş karbonhidratlar gibi işlenmiş besin tüketiminin artması ile obezite gösterilebilir. $\mathrm{Bu}$ çalışmada katılımcıların BKİ'leri incelendiğinde çoğunluğun fazla kilolu olduğu bulunmuştur. Artan şeker alımının artmış obezite ve tip 2 DM riski ile ilişkili olduğuna dair kanıtlar göz önüne alındığında, IDF (Uluslararası Diyabet Federasyonu) önerilen şeker alımını, günlük enerji gereksiniminin \%5'ine kadar azaltmayı ve ulusal hükümetleri şeker tüketimini azaltmak için politikalar uygulamaları için çağrıda bulunmaktadır. ${ }^{21}$ 
Son yıllarda yapılan çalışmalar şeker eklenmiş içeceklerin (meyve suyu da dahil) tüketimi ile tip 2 DM riski artışı arasında güçlü ilişkiler olduğunu ve şeker tüketiminin DM prevalansıyla ilişkili olduğunu göstermektedir. ${ }^{21-23}$ Yapılan bir prospektif kohort çalışmasının meta analizinde yüksek miktarda şekerli içecek tüketen kadın ve erkeklerde, düşük miktarlarda tüketenlere kıyasla \%26 daha fazla Tip 2 DM geliştirme riski bulunmuştur. ${ }^{24}$

Bireyler ağırlık kontrolü sağlamak, günlük enerji alımını kısıtlamak, kan şekerini yükseltmeden tatlı tüketebilmek gibi nedenlerle tatlandırıcı veya tatlandırıcı içeren diyet/diyabetik ürünleri tercih edebilmektedir. Diyabetlilerin yapay tatlandırıcı kullanımını araştıran bir çalışma sonucuna göre; katılımcilarda yapay tatlandırıcı tüketim prevalansı $\% 96$ ve tatlandırıcı tüketiminin erkeklerde ve tip 1 DM'lilerde daha yüksek olduğu bulunmuştur. ${ }^{25} \mathrm{Bu}$ çalışmada ise tatlandırıcı kullanmayanların oranı \%79.1 olarak bulunmuştur. $\mathrm{Bu}$ sonuç, tatlandırıcılar hakkında çıkan haberlerin tüketicileri olumsuz yönde etkilediğini düşündürtmektedir.

Kayhan ve Alphan'ın çalışmasında hastaların hazır diyabetik ürünlerden tip 2 DM'lilerin en fazla diyabetik bal-reçel sonrasında diyabetik pasta/kek ve diyabetik çikolata tercih ettikleri tip 1 DM'lilerin ise en fazla diyabetik pasta/kek tercih ettikleri belirlenmiştir. ${ }^{26}$ Geçen yaklaşık on beş yıl içerisinde tüketicilerin diyet/diyabetik ürün tercihlerinin değişkenlik gösterdiği söylenebilir. Bu çalışmada diyabetlilerin sırasıyla en fazla diyet bisküvi/kraker, daha sonra diyet içecek, light meyveli yoğurt, diyet dondurma, diyabetik reçel/marmelat, diyet çikolata, diyet sütlü tatlı ve diyet hamurlu tatlı tükettiği görülmüştür.

Çalışmaya katılan DM'lilerin tatlandırıcı ve tatlandırıcı içeren ürün kullanma nedenleri sorgulandığında en fazla tercih etme nedenlerinin şeker içermemesi olduğu saptanmıştır. Bu sonuca göre DM'lilerin ürünleri tercih ederken kan şekeri regülasyonlarını sağlama amacı taşıdıkları ve günlük diyetlerinde enerji artış1 yapmaktan kaçındıkları söylenebilir.

ABD'de düşük enerjili yiyecek ve içecek kullanıcılarının diyet kalitesini belirlemek için bir çalışma yapılmıştır. Çalışma, "Bireyler Tarafından Yiyecek Alımlarının Araştırılması" temelli olup düşük enerjili tatlandırıcılı (DET) ürün tüketicileri ile şekerli ürün tüketicilerini kıyaslamaktadır. $\mathrm{Bu}$ çalışmanın sonucuna göre düşük enerjili yiyecek ve içecek tüketenlerin ağırlıklı olarak kadın, beyaz tenli, daha yaşlı, eğitimli ve daha yüksek sosyoekonomik statüye sahip ve daha fazla diyet takviyesi yaptıkları bildirilmiştir. Bununla birlikte, DET'li ürün kullanıcılarının ağırlık kaybı veya koruma amacı taşıdıkları görülmüştür. ${ }^{27}$ Bizim çalışmamızda ise katılan bireylerin çoğunluğunu ilköğretim mezunu, fazla kilolu/obez kadınlar oluşturmaktadır.

\section{SONUÇ}

Sonuç olarak araştırmacı gözlemi olarak çalışmaya dahil olan diyabetlilerin tatlandırıcıların genel özellikleri, kullanım koşulları, diyet/diyabetik ürünler hakkında yeterli bilgiye sahip olmadıkları, bu ürünler yerine az miktarlarda da olsa şeker (sukroz) içeren yiyecek ve içecekleri tercih ettikleri saptanmıştır. Tatlandırıcı ve diyet ürünlerinin dünyadaki kullanımının ağırlık kontrolü yapmak isteyenler, obezler ve DM'liler tarafından arttığı, buna rağmen bu çalışmada tatlandırıcı kullanımının oldukça düşük olduğu bulunmuştur. Bunun nedeni olarak; yazılı ve görsel medyada çıkan haberler, sağlık çalışanlarının yeterli bilgisinin olmayışı, sağlık sorunlarına ve özellikle kansere yol açabileceği endişesinin yer aldığı düşünülmektedir.

Diyabetlilerin tedavilerinin temelini oluşturan yaşam tarzı değişiklikleri ve sağlıklı beslenme alışkanlıklarını içeren tıbbı beslenme tedavisini ömür boyu uygulamaları gerekir. Bu çerçevede FDA tarafından onaylanan enerji içermeyen tatlandırıcıları içeceklerinde ve evde yapılan tatlılarda kullanabilirler. Tatlandırıcı ve diyet/diyabetik ürünler ile ilgili daha geniş kitlelerin bilgilendirilmesine ve daha bu alanda fazla çalışma yapılmasına ihtiyaç vardır.

\section{KAYNAKLAR}

1. Kılıçlar A, Şahin A, Sarıkaya S, Bozkurt İ. Kişilik Tiplerinin Tat Tercihlerine Etkisi. Journal of Tourism and Gastronomy Studies. 2017;5(3):93117.

2. Weihrauch MR, Diehl V. Artificial sweeteners-do they bear a carcinogenic risk. Annals of Oncology. 2004;15(10):1460-1465.

3. Satman İ, Alagöl F, Ömer B, Kalaca S, et al. Türkiye'de diyabet, obezite, hipertansiyon ve endokrinolojik hastalıklar prevalans çalışması (TURDEP-II), 2011.

4. American Diabetes Association (ADA). Statistics about diabetes overall numbers, diabetes and prediabetes. http://www.diabetes.org/diabetesbasics/statistics/?loc=db-slabnav?referrer=https:// www.google.com.tr/. Erişim Tarihi: 3 Eylül 2019.

5. Alphan ME. Diabetes mellitus ve beslenme tedavisi. Alphan ME ed. Hastalıklarda beslenme tedavisi. İstanbul: Hatipoğlu Yayınc1lık; 2013: 415-508.

6. Chattopadhyay S, Raychaudhuri U, Chakraborty R. Artificial sweeteners-a review. Journal of food science and technology. 2014; 51(4): 611-621.

7. Bellisle F. Intense sweeteners, appetite for the sweet taste, and relationship to weight management. Current obesity reports. 2015; 4(1): 106-110.

8. U.S. Food and Drug Administration. Highintensity sweeteners. 2014. https://www.fda.gov/ food/food-additives-petitions/high-intensitysweeteners. Erişim Tarihi: 3 Eylül 2019. 
9. By Mayo Clinic Staf. Artificial sweeteners and other sugar substitutes. 2018. http://www.mayo clinic.org/healthy-lifestyle/nutrition-and-healthyeating/in-depth/artificial-sweeteners/art-20046936 Erişim Tarihi: 9 Eylül 2019.

10. Alphan E. Tatlandırıcı içeren özel beslenme amaçlı gidalar. Diyabet yıllı̆̆ $ı$. 2004-2005.

11. Fitch C, Kathryn SK. Position of the Academy of Nutrition and Dietetics: use of nutritive and nonnutritive sweeteners. J Acad Nutr Diet. 2012; 112(5):739-758.

12. U.S. Food and Drug Administration (FDA). Additional Information about High-Intensity Sweeteners Permitted for Use in Food in the United States. 2018. https://www.fda.gov/food/foodadditives-petitions/additional-information-abouthigh-intensity-sweeteners-permitted-use-foodunited-states Erişim Tarihi: 4 Eylül 2019.

13. Gardner C, Rosett WJ, Gidding SS, et al. Nonnutritive sweeteners: current use and health perspectives. Circulation 2012;126(4):509-519.

14. The Global Diabetes Community. Nutritive and non-nutritive sweeteners. http://www.diabetes. co.uk/sweeteners/nutritive-and-nonnutritivesweeteners.html. Erişim Tarihi: 11 Eylül 2019.

15. Grembecka M. Natural sweeteners in a human diet. Rocz Panstw Zakl Hig. 2015;66(3):195-202.

16. Grembecka M. Sugar alcohols-their role in the modern world of sweeteners: a review. Eur Food Res Technol. 2015;241:1-14.

17. Özel HG. Tip 1 diabetes mellitus ve beslenme. Diyabet ve Obezite. 2010;23-24:1-7.

18. Reid AE, Chauhan B, Rabbani R, et al. Early exposure to nonnutritive sweeteners and long-term metabolic health: a systematic review. Pediatrics. 2016;137(3):1-12.
19. World Health Organisation (WHO). Obesity and Overweight. 2018. https://www.who.int/newsroom/fact-sheets/detail/obesity-and-overweight Erişim Tarihi: 3 Eylül 2019.

20. American Diabetes Association (ADA). Statistics About Diabetes.

https://www.diabetes.org/resources/statistics/statis tics-about-diabetes. Erişim Tarihi: 5 Eylül 2019.

21. International Diabetes Federation. IDF Framework for Action on Sugar. 2016. https://www.idf.org/images/site1/content/Framew ork-for-Action-on-Sugar-010615.pdf Erişim Tarihi: 5 Eylül 2019.

22. Page KA, Chan O, Arora J, et al. Effects of fructose vs glucose on regional cerebral blood flow in brain regions involved with appetite and reward pathways. JAMA. 2013;309(1):63-70.

23. Schulze MB, Manson JAE, Ludwig DS, et al. Sugar-sweetened beverages, weight gain, and incidence of type 2 diabetes in young and middleaged women. JAMA. 2004;292(8):927-934.

24. International Diabetes Federation. IDF Diabetes Atlas. 2015, Seventh Edition: 11-129.

25. Romo-Romo A, Almeda-Valdés P, Brito-Córdova GX, et al. Prevalence of non-nutritive sweeteners consumption in a population of patients with diabetes in Mexico. Gac Med Mex. 2017;153:5668.

26. Kayhan F, Alphan E. Diyabetli hastalarda yapay tatlandırıc1 kullanımı. PTT Hast Tip Der. 2001;23(2):81-89.

27. Anderson GH, Foreyt J, Sigman-Grant M, Allison DB. The use of low-calorie sweeteners by adults: impact on weight management. $J$ Nutr. 2012;142(6): 1163-1169. 